\title{
NONLINEAR DYNAMICS IN FINANCIAL TIME SERIES AND UNIT ROOT \\ TESTS: CASE OF BORSA ISTANBUL SECTORAL PRICE-EARNING RATIOS
}

DOI: 10.17261/Pressacademia.2015414370

\section{Mehmet Ozcan'}

'Gazi University. mehmetozcan@gazi.edu.tr

\section{Keywords}

Price-earning ratio, structural break threshold regression, nonlinear econometrics, nonlinear unit root tests

JEL Classification

G10, C58, C22

\begin{abstract}
Because of the variables which are falling within the scope of finance and the analysis are more reliable which are performed with high frequency series, financial time series take into special attention of empirical studies. Observed nonlinear effects on series are one of the popular subject for time series econometrics in the last years. Nonlinear dynamics are studied under two main topics in the literature which are Structural Break and Regime Switching. Structural Break is the best known nonlinear econometrics subject in Turkey. In this paper, structural break and regime switching dynamics that can be observed in time series are investigated and unin root test which are developed according to this dynamics are mentioned. At the end of the paper, price-earning ratio of Borsa Istanbul 100 Index dealt with on a sectoral basis and the nonlinear unit root tests are applied on related time series.
\end{abstract}

\section{FINANSAL ZAMAN SERILERINDE DOĞRUSAL OLMAYAN DINAMIKLER VE BíRIM KÖK TESTLERI: BORSA ISTANBUL SEKTÖREL FIYAT-GETIRi ORANLARI ÖRNEĞi}

\author{
Anahtar Kelimeler \\ Fiyat-getiri oranı, yapısal \\ kırılma, eşik regresyon, \\ doğrusal olmayan \\ ekonometri, doğrusal \\ olmayan birim kök \\ testleri
}

JEL Sınıflandırması G10, C58, C22

\section{ÖZET}

Finansın ilgi alanına giren değişkenlerin sık aralıklar ile güncellenmesi ve yüksek frekansa sahip seriler ile gerçekleştirilen analizlerin daha sağlıklı olması sebebiyle finansal zaman serileri ampirik çalışmaların özel ilgisini çekmektedir. Zaman serileri ekonometrisi için son yıllarda popüler olan konulardan biri de serilere gözlenen doğrusal olmayan etkilerdir. Doğrusal olmayan dinamikler Yapısal Kırılma ve Rejim Değişimi adlarında literatürde iki ana başlık altında incelenmektedir. Bu başlıklardan Yapısal Kırılma Türkiye'de en çok bilinen doğrusal olmayan ekonometri konusudur. Bu çalışmada zaman serilerinde gözlemlenen yapısal kırılma ve rejim değişim dinamikleri incelenmiş ve bu dinamikler çerçevesinde geliştirilen doğrusal olmayan birim kök testlerine değinilmiştir. Çalışmanın sonunda Borsa İstanbul 100 Endeksi fiyat-getiri oranları sektörel bazda ele alınmış ve ilgili serilere doğrusal olmayan birim kök testleri uygulanmıştır. 


\section{GíRiş}

İktisat literatüründe ekonometrik yöntemlerin katılması ile insanlığın iktisadi ilişkileri hakkında öne sürülen iddia, hipotez ve teoriler toplanan veriler ve keşfedilen istatistiki araç ve analizler ile sınanmış, iktisadi bilgi bu analizlerden elde edilen bilgiler ile yeniden şekillenmiştir. Ampirik analiz olarak adlandırılan bu çalışmalar zamanla iktisadın tüm kollarına yayılmıştır. Bu kollardan biri de şüphesiz finanstır. Finans biliminin incelediği finansal göstergeler olarak isimlendirilen değişkenler, sık frekansta gözlenmeleri ve doğaları gereği diğer makro iktisadi göstergelere oranla daha yüksek değişkenlik göstermeleri sebebi ile özellikle zaman serisi ekonometrisinin uygulama alanı bulabildiği değişkenlerdir. İncelenecek zaman serilerinin doğrusal olduğu varsayımı altında gerçekleştirilen ampirik çalışmalar bugün oldukça yaygındır. Ancak özellikle Amerika Birleşik Devletleri (ABD) ve Birleşik Krallık (BK) gibi ülkelerde seksenli yılların başlarından itibaren hızla gelişen ve uygulamalı finans çalışmaları çerçevesinde popüler hale gelen doğrusal olmayan zaman serisi literatürü göze çarpmaktadır. Ülkemizde ise bu literatürün yapısal kırılma adı verilen dalı oldukça bilinirken, rejim değişimi olarak adlandırılan diğer dalı henüz gelişme aşamasındadır. Değişimin oldukça hızlı olduğu, gözlem değerleri arasındaki zaman aralığının en kısa olduğu finansal değişkenlerde bahsi geçen doğrusal olmayan zaman serisi dinamiklerini uygulamalı çalışmalara dahil etmek, daha sağlıklı analizler gerçekleştirmek ve daha tutarlı öngörülerde bulunabilmek için gereklidir. Bu bağlamda, çalışmada amaçlanan, parametreler cinsinden doğrusal olmayan modeller çerçevesinde doğrusal olmayan zaman serisi süreçlerini açıklamak ve bu süreçlere bağlı geliştirilen birim kök testleri yardımı ile doğrusal olmayan dinamiklerin uygulamalı çalışmalarda dikkat edilmesi gereken unsurlar olduğuna dikkat çekmektir.

Zaman serilerindeki durağanlık konusu yakından irdelenecek olursa durağanlık ve birim kök kavramlarının çıkış noktalarına odaklanmakta fayda vardır. Durağanlık konusu literatürde tartışımaya başlandığında ampirik çalışma gerçekleştiren araştırmacılar serilerde var olan deterministik karaktere sahip trend, mevsimsellik ve döngüsel hareketlerin arındırılması durumunda serilerin birim kök probleminden kurtulacağı kanısına kapılıp çalışmalarına devam etmişlerdir. Ancak deterministik bileşenler temizlendikten sonra bile makro iktisadi değişkenlerin rassal yürüyüş adı verilen ve durağan olmayan sürece benzerliğinin ortaya konması yetmişli yılların sonlarında uygulamalı çalışmaları derinden etkilemiştir. Sonuç olarak durağan olmayan veriler ile gerçekleştirilecek ekonometrik çalışmalar sahte, sağlıklı olmayan sonuçlar vermesi beklenebilir. Bu bulgular analize başlamadan önce ele alınan iktisadi göstergelere ait verilerin durağan olup olmadığının araştırılmasının çok önemli olduğunu göstermiş ve makroiktisat alanında yapılan tüm ampirik çalışmaların özelliklerini sonsuza kadar değiştirmiştir (Kennedy, 2006: 355-356).

Durağan olmayan zaman serilerinin yarattığı problemlerin fark edilmesi iktisadın hemen hemen her alanında sarsıcı bir etki yaratmıştır. Bu çalışmada da özünde doğrusal olmayan zaman serilerinin doğrusallık varsayımı altında geliştirilmiş birim kök sınamalarına tabi tutulması sonucu elde edilen sonuçların sağlıklı olmayacağı gerçeğini göstermek ve bu yönde bir farkındalık yaratmaktır. Böylece doğrusal olmayan süreçlerin özellikle finans alanında gerçekleştirilen uygulamalı çalışmaların tutarlıı̆ı konusunda ne kadar önemli olduğunu belirtmek amaçlanmıştır. Bu amaçla çalışmada, doğrusal birim kök testlerinden 
literatürde en sık kullanılan Genişletilmiş (Augmented) Dickey Fuller Testi'ne (ADF), yapısal kırılma için literatürde en sık kullanılan Zivot ve Andrews (1992) birim kök testine ve rejim değişimi altında literatürde en sık kullanılan Caner ve Hansen (2001) birim testine yer verilmiştir.

Çalışmanın izleyen ikinci bölümünde doğrusal olmayan dinamikler ve doğrusal olmayan modellere değinilecektir. Ardından üçüncü bölümde birim kök testlerinin teorik açıklamaları yapılacaktır. Dördüncü bölümde ise Borsa İstanbul 100 Endeksi sektörel fiyatgetiri oranları serilerine doğrusal ve doğrusal olmayan birim kök testleri uygulanacaktır. Beşinci bölümde ise elde edilen sonuçlar teorik açıklamalara bağı kalınarak yorumlanacaktır.

\section{DOĞRUSAL OLMAYAN DINAMIKLER}

Ekonometri zaman serisi analizi literatüründe doğrusal olmayan modelleme iki grupta incelenmektedir. Bunlardan ilki zaman serilerinde meydana gelen ve kırılma olarak adlandırılan ani değişimlerin incelendiği Yapısal Kırılma (Structural Break) çalışma grubudur. İkinci grup ise Rejim Değişim (Regime Switching) olarak adlandırılan, zaman serilerinin belli bir eşik değerin altında farklı, üstünde farklı davranışlar sergilemesi ile ortaya çıkan rejimlerin incelenmesine odaklanan çalışma grubudur.

Yukarıda bahsi geçen doğrusal olmayan dinamikleri incelemeden önce ekonometride doğrusal olmama ne demek sorusuna yeterli bir cevap verilmelidir. Doğrusal olmama durumu ekonometrik modellerde iki açıdan ele alınır. Bunlardan ilki değişkenler cinsinden doğrusal olmayan modeller. Bu tip modellere aşağıdaki gibi örnekler sunulabilir:

$$
\begin{aligned}
& y_{t}=\alpha_{0}+\alpha_{1} x_{t}+\alpha_{2} x_{t}^{2}+\varepsilon_{t} \\
& y_{t}=\gamma_{0}+\gamma_{1} 1 / x_{t}+v_{t} \\
& y_{t}=\phi_{0}+\phi_{1} \sqrt{x_{t}}+w_{t}
\end{aligned}
$$

Verilen örnek modellerden görüleceği üzere, modellerde yer alan açıklayıcı değişkenler doğrusal değil doğrusal olmayan formda modelde yer almaktadırlar. Böylece doğrusal olmayan değişken(ler) ile yine doğrusal olmayan (veya doğrusal olan) değişkenler arasındaki ilişki ortaya konur. Ancak dikkat edilmelidir ki bu modellerde parametre tahminleri değişmez zaman içinde hep sabit kalır. Dolayısıyla doğrusal veya değil değişkenler arasındaki ilişki zaman içinde değişmez. Bu modeller En Küçük Kareler (EKK) yöntemi ile tahmin edilebilirler ve bu modeller hakkında detaylı bilgiler günümüz ekonometri ders kitaplarının çoğunda fonksiyonel formlar başlığı altında yer almaktadır (Ramanathan, 2002: 232).

Ekonometride doğrusal olmayan dinamiklerin incelendiği, tahmini ve yorumu nispeten daha karmaşık olan modeller parametreler cinsinden doğrusal olmayan modellerdir. Bu modellerde parametre tahminleri zaman içinde değişmektedir. Dolayısıyla doğrusal olmayan değişkenler değil değişkenler arasındaki ilişkidir. Bu sebeple değişkenler arasındaki ilişkiyi ortaya koyan parametre tahminleri zaman içinde farklılaşır. Bu çalışmada üzerinde durulacak yapısal kırılma ve rejim değişimi dinamiklerini ortaya koyan modeller bu gruba girmektedirler. Bu önemli ve temel ayrımın ortaya konmasının ardından çalışmanın odaklandığı iki doğrusal olmayan dinamiğin daha yakınan incelenebilir. 
Doğrusal olmayan dinamiklerin ilki olan yapısal kırılma kavramı ortaya çıkış tarihi ile daha eski olmasından ötürü, kantitatif iktisatçıların ilk keşfettikleri doğrusal olmayan dinamiktir. Zaman içinde $t_{B}$ anında gerçekleşen bir yapısal kırılma durumunu modelleyen iki eşitlik aşağıdaki gibi gösterilebilir:

$$
\begin{aligned}
& y_{t}=\alpha_{0}+\alpha_{1} x_{t}+\gamma D_{t B}+\varepsilon_{t} \\
& y_{t}=\alpha_{0}+\alpha_{1} x_{t}+\gamma\left(x_{t} D_{t B}\right)+\varepsilon_{t}
\end{aligned}
$$

Yukarıdaki modellerde yapısal kırılma kuklası $D_{t B}$ aşağıdaki gibi tanımlanır:

$$
D_{t B}=\left\{\begin{array}{l}
1 \quad \text { ĕger } t>t_{B} \text { ise } \\
0 \quad \text { diğer durumlarda }
\end{array}\right.
$$

Buna göre model (a) ve model (b)'deki yapısal değişimler yorumlanabilir. Model (a) için $t_{B}$ anında gerçekleşen yapısal kırılmanın öncesi sabit terim yalnızca $\alpha_{0}$ ile ifade edilirken, kırılma sonrası $\left(\alpha_{0}+\gamma\right)$ ile ifade edilmektedir. Böylece sabit parametresi zaman içinde aynı kalmamakta değişmektedir. Benzer durum eğim parametresi olan $a_{1}$ için de geçerlidir. Bu kez model (b) göz önüne alınacak olursa yapısal kırılma anı $t_{B}$ öncesi model (b)'de eğim parametresi sadece $a_{1}$ iken, yapısal kırılma sonrası eğim parametresi değişmekte ve $\left(\alpha_{1}+\gamma\right)$ olmaktadır. Dolayısıyla her iki örnek model ile gösterildiği gibi zaman serilerinde meydana gelen yapısal kırılma durumu parametreler cinsinden doğrusal olmayan modellerin kurulması ve tahmin edilmesini gerekli kılmaktadır.

$\mathrm{Bu}$ doğrultuda çalışmanın odaklanacağı diğer doğrusal olmayan dinamik olan rejim değişimi konusunu oluşturan Eşik Otoregresyon (TAR) ve Eşik Regresyon (TRM) modeller ilk olarak Tong (1978), Tong ve Tim (1980) ve Tong (1983) çalışmalarında ortaya konmuş doğrusal olmayan zaman serisi modelleridir. Bu modeller rejim değişim modelleri olarak bilinirler.

Temel olarak TAR ve TRM modellerinin çalışma prensibi, doğrusal olmayan davranışı, doğrusal modeli parça parça tahmin ederek açıklamaya dayanır. Ekonometri lisans müfredatında sıkça bahsedilen yapısal kırılmaları ifade etmek amacı ile kukla değişkenlerin kullanılması, TAR ve TRM modellerinin tahmin sürecine benzer bir yöntemdir. Aralarındaki fark kullanılan kukla değişkenin oluşturulmasında yatmaktadır. Klasik kukla değişken içeren bir modelde kukla değişken zamana göre oluşturulurken, örneğin $t$ anındaki bir yapısal kırılmada, t anından önceki zamanlarda 0 , sonraki zamanlarda 1 değerini alan bir kukla değişken oluşturulur. TAR ve TRM modellerinde belli bir açıklayıcı değişkenin aldığı değerlere göre oluşturulan kukla değişken kullanılır. Bundan ötürü tahmin sürecini açıklamadan önce TAR ve TRM modellerine özgü bir iki kavram izah edilmelidir. Bunlardan ilki eşik değişkenidir. Eşik değişkeni (Threshold Variable), açıklayıcı değiş̧enler arasında yer alan ve sahip olduğu değerlere göre modelin doğrusal dışı yapısını tahmin sürecine katan değişkendir. Eşik değişkeni bünyesinde bir diğer önemli kavram olan eşik değerini (Threshold Value) barındırır. Eşik değeri, önceden belirlenen ya da parametre olarak sonradan tahmin edilen eşik değişkeninin değerlerinden biridir. Model, eşik değişkeninin, 
eşik değerine göre ikiye ayrımasına dayanılarak oluşturulur. Tong tarafından ortaya atılan temel TAR modelini şu şekilde gösterebiliriz:

$$
y_{t}= \begin{cases}\alpha_{10}+\alpha_{11} x_{t}+\varepsilon_{1 t} & \text { eğer } x_{t-1}>\tau \text { ise } \\ \alpha_{20}+\alpha_{21} x_{t}+\varepsilon_{2 t} & \text { eğer } x_{t-1} \leq \tau \text { ise }\end{cases}
$$

Yukarıdaki örnek basit regresyon modelinin Eşik Regresyon olarak biçimlendirilmiş halidir. Burada eşik değişkeni $x_{t-1}$ 'dir. Eşik değişkenin aldığı değerlerden biri olan $\tau$ da eşik değeridir (parametresidir.). Buna göre eşik değişkeni $x_{t-1}$ 'in eşik değeri $\tau$ 'dan büyük değerleri için uygun regresyon modeli $y_{t}=\alpha_{10}+\alpha_{11} x_{t}+\varepsilon_{1 t}$ iken, tam tersi durumda yani eşik değişkeni $y_{t-1}$ 'in eşik değeri $\tau$ 'dan küçük değerleri için uygun regresyon modeli ise $y_{t}=\alpha_{20}+\alpha_{21} x_{t}+\varepsilon_{2 t}$ biçiminde olur. Eşik Regresyon modelinde yer alan iki ayrı denklemin sahip olduğu hata terimlerinin varyanslarının eşit olması varsayımı altında ( $\operatorname{var}\left(\varepsilon_{1 t}\right)=\operatorname{var}\left(\varepsilon_{2 t}\right)$ ) bu iki denklem bir kukla değişken yardımı ile tek denklem olarak ifade edilebilir:

$I_{t}=\left\{\begin{array}{l}1 \text { eğer } x_{t-1}>\tau \text { ise } \\ 0 \text { eğer } x_{t-1} \leq \tau \text { ise }\end{array}\right.$

$y_{t}=\alpha_{10} I_{t}+\alpha_{11} I_{t} x_{t}+\alpha_{20}\left(1-I_{t}\right)+\rho_{21}\left(1-I_{t}\right) \mathrm{x}_{t}+\varepsilon_{t}$

Bu modelde anlaşılacağı üzere $I_{t}$ eşik değer kuklasıdır.

Eşik regresyon modellerinin tahmin süreci öncelikle eşik değerinin bilinip bilinmemesine göre değişir. Eşik değerinin bilinmesi durumunda En Küçük Kareler (EKK) yöntemi rahatılıkla TAR modellerinin tahmininde kullanılabilir. Bunun için öncelikle modelin oluşturulması gerekir. Model ise eşik değişkenin bilinen eşik değere göre yeniden biçimlendirilmesi ile kurulur. Eşik değerinin bilinmemesi durumu literatürde daha sık karşılaşılan bir sorundur. Bu bilinmezlik ise S.K. Chan'nin 1993 yılında gerçekleștirdiği çalışmasında önerdiği basit fakat 90'lı yılların bilgisayar teknolojisine göre uygulanması zor bir metodoloji ile çözülmüştür. Günümüzde ise daha güçlü bilgisayarlar ve yazılımlar ile eşik modellerin tahmininde Chan (1993) yönteminin uygulanışı daha kolay ve popüler hale gelmiştir. Bu yönteme göre önce eşik değişken olarak seçilen serinin değerleri küçükten büyüğe sıralanır. Yüzde $15^{\prime}$ lik dilimlerde yer alan en küçük ve en büyük değerler diziden çıkarılır. Geriye kalan değerler tek tek eşik değer kabul edilerek eşik regresyon modelleri tahmin edilir. Tahmin edilen modeller içinde en küçük kalıntı kareler toplamına sahip olan model seçilir ve doğrusal olmayan rejim değişimi ilişkisini temsil eden model tahmini olarak kabul edilir.

Eşik regresyon modelleri hakkında değinilmesi gereken son husus eşik değişkenin farkı alınarak da eşik regresyon modellerin tahmin edilebileceği hususudur:

$$
y_{t}= \begin{cases}\alpha_{10}+\alpha_{11} x_{t}+\varepsilon_{1 t} & \text { eğer } \Delta x_{t-1}>\tau \text { ise } \\ \alpha_{20}+\alpha_{21} x_{t}+\varepsilon_{2 t} & \text { eğer } \Delta x_{t-1} \leq \tau \text { ise }\end{cases}
$$


Bu modelde eşik değişken $x_{t-1}$ değil $\Delta x_{t-1}$ 'dir. Buradaki amaç eşik değişkenin aldığı cari değerlere göre değil, eşik değişkenin belli dönemler içinde gözlem değerleri arasındaki değişime göre doğrusal olmayan modelleme yapmaktır. Bu modeller Momentum Eşik Regresyon modelleri adı verilir ve rejim değişimi için geliştirilen birim kök testleri bu tür modelleri kullanır.

\section{BIRIM KÖK TESTLERI KURAMSAL ÇERÇEVE}

Bir zaman serisi zamanın farklı anlarında aynı dağılıma sahipse bu seriler güçlü durağan olarak nitelendirilirler (Akdi,2010: 20). Ancak serilerin güçlü durağan olması genellikle sağlanamadığından serinin zayıf durağan olması durağanlık olarak nitelendirilir ve ekonometrik bir analizin yapılabilmesi için yeterli bir koşuldur.

Bir zaman serisinin durağan olması, ortalamasıyla varyansı zaman içinde değişmeyen ve iki dönem arasındaki kovaryansı, kovaryansın hesaplandığı döneme değil yalnızca iki dönem arasındaki uzaklığa bağı olan olasılıklı bir sürece sahip olmasıdır (Gujarati, 2006:713). Bir zaman serisinin durağan olması matematiksel olarak aşağıdaki gibi ifade edilebilir:

$$
\begin{aligned}
& E\left(Y_{t}\right)=\mu \\
& V\left(Y_{t}\right)=\sigma^{2} \\
& E\left(Y_{t}-\mu\right)\left(Y_{t-k}-\mu\right)=\gamma_{k} \quad ; \forall t, k i c ̧ i n
\end{aligned}
$$

Bir ekonometrik modelde hata terimine ilişkin varsayımların sağlanması, aynı zamanda durağanlığı da sağlamaktadır. Çünkü hata teriminin ortalaması sıfır ve varyansı sabit ise durağandır, dolayısıyla hata terimine bağlı olan serilerde durağan olacaktır.

Bu bölümde çalışmada kullanılacak birim kök testlerin kuramsal açıklamaları yapılacaktır. Önce literatürde en sık kullanılan doğrusal bir birim kök testi olan Genişletilmiş (Augmented) Dickey Fuller Testi (ADF) üzerinde durulacaktır. Ardından yapısal kırılma durumu altında serilerin durağanlığını inceleyen Zivot-Andrews (1992) birim kök testi incelenecektir. Son olarak zaman serilerindeki rejim değişimi davranışını temel alan CanerHansen (2001) birim kök testi açıklanacaktır.

\section{ADF Birim Kök Testi}

Bir zaman serisinde birim kökün varlığının araştırılmasında kullanılan yöntemlerden birisi Dickey-Fuller testidir. Dickey D.A. ve W.A. Fuller (1979) tarafından önerilen yöntem AR(1) süreci modeline dayanmaktadır (Akdi,2010:278). Dickey-Fuller testine en büyük eleştiri modelin otokorelasyon durumunu içermemesidir. Bu yüzden modele değişkenin gecikmeli değerleri eklenerek Dickey-Fuller testi geliştirilmiş ve Genişletilmiş Dickey ve Fuller (1981) testi olarak yeniden sunulmuştur.

$\mathrm{AR}(\mathrm{p})$ süreci modeline $\alpha_{p} Y_{t-p+1}$ eklenip çıkarılırsa;

$$
Y_{t}=\alpha_{0}+\alpha_{1} Y_{t-1}+\alpha_{2} Y_{t-2}+\ldots+\alpha_{p-2} Y_{t-p+2}+\left(\alpha_{p-1}+\alpha_{p}\right) Y_{t-p+1}-\alpha_{p} \Delta Y_{t-p+1}+\varepsilon_{t}
$$


elde edilir. Modele $\left(\alpha_{p-1}+\alpha_{p}\right) Y_{t-p+2}$ ekleyip çıkarılırsa ve model bu işlemlerle düzenlenirse model aşağıdaki gibi olur:

$Y_{t}=\alpha_{0}+\alpha_{1} Y_{t-1}+\alpha_{2} Y_{t-2}+\ldots+\left(\alpha_{p-2}+\alpha_{p-1}+\alpha_{p}\right) Y_{t-p+2}-\alpha_{p-1} \Delta Y_{t-p+2}-\alpha_{p} \Delta Y_{t-p+1}+\varepsilon_{t}$

İşlemlere bu şekilde devam edilir ve model yeniden düzenlenecek olursa;

$\Delta Y_{t}=\alpha_{0}+\delta Y_{t-1}+\sum_{i=2}^{p} \beta_{i} \Delta Y_{t-i+1}+\varepsilon_{t}$

(4)

modeline ulaşılır. Dickey-Fuller testinde olduğu gibi $H_{0}: \delta=0$ hipotezine karşı $H_{A}: \delta<0$ hipotezi test edilir. Eğer istatistiksel olarak $\delta=0$ ise serinin birim köke sahip olduğu yani durağan olmadığı söylenebilir.

Ancak bu modelde $\mathrm{p}$ gecikme uzunluğunun belirlenmesi sorun oluşturabilmektedir. Gecikme uzunluğu belirlenirken Akaike ve Schwarz Bilgi Kriterlerinden (AIC ve SIC) yararlanılmaktadır. Buradaki temel düşünce (4) denklemindeki hata teriminin otokorelasyonsuz olmasını sağlayacak kadar gecikme teriminin modele katılmasıdır. ADF ve DF test istatistikleri aynı asimptotik dağılım özelliklerini taşıdığı için kritik değerleri de aynı olmaktadır. Yani aynı kritik değer tablosunu kullanmaktadır.

ADF testinde de DF testinde olduğu gibi modelin sabit terim veya trend içermesine bağlı olarak 3 regresyon modeli kullanılır (Enders, 2010:207):

$$
\begin{aligned}
& \Delta Y_{t}=\delta Y_{t-1}+\sum_{i=2}^{p} \beta_{i} \Delta Y_{t-i+1}+\varepsilon_{t} \\
& \Delta Y_{t}=\alpha_{0}+\delta Y_{t-1}+\sum_{i=2}^{p} \beta_{i} \Delta Y_{t-i+1}+\varepsilon_{t} \\
& \Delta Y_{t}=\alpha_{0}+\alpha_{2} t+\delta Y_{t-1}+\sum_{i=2}^{p} \beta_{i} \Delta Y_{t-i+1}+\varepsilon_{t}
\end{aligned}
$$

\section{Zivot - Andrews (1992) Birim Kök Testi}

Yapısal kırılmaların varlığı durumunda geliştirilen birim kök testleri; Peron (1989), Christiano (1992), Banarjee, Lumsdaine ve Stock (1992), Zivot ve Andrews (1992), Peron ve Vogelsang (1992) ve Peron (1997) testleridir. Bu testler zaman kırılmasının içsel ya da dışsal olarak belirlenmesine göre ikiye ayrılmaktadır. Bu ayrım, aşağıdaki şemada gösterilmiştir: 


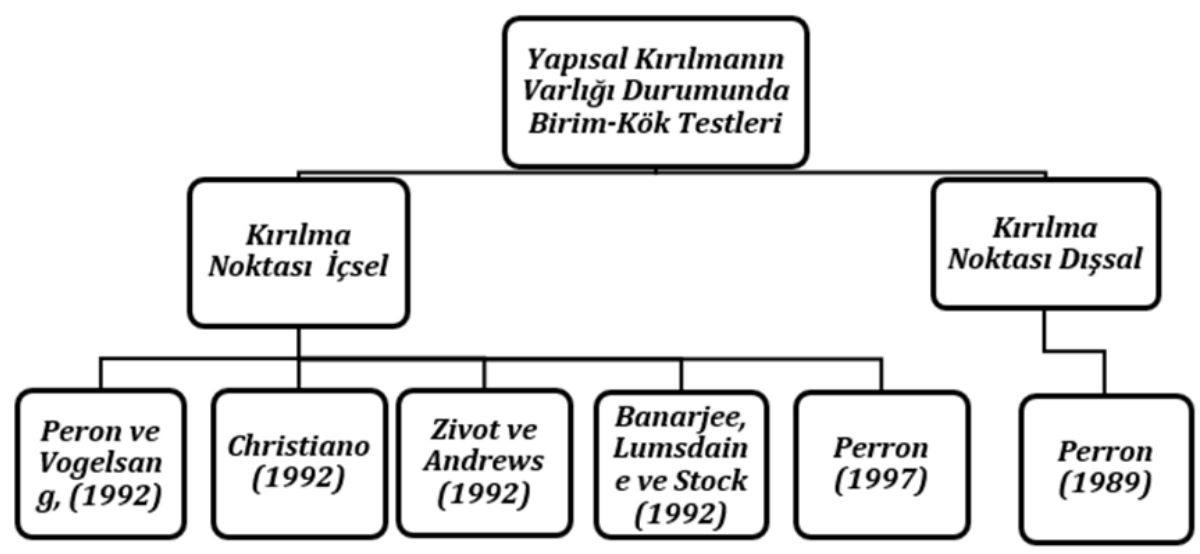

Şekil 1: Yapısal Kırılmanın Varlığı Durumunda Birim Kök Testleri

Perron (1989), bir serinin birim köke sahip olduğunu gösteren hipotezi test etmek için, belirli bir zamanda meydana gelen dışsal yapısal kırımanın dikkate alındığı bir yöntem geliştirmiştir (Yavuz, 2006). Perron'un geliştirdiği yönteme göre ekonomide gerçeklesen yapısal değişiklikler önceden bilinmektedir.

Zivot ve Andrews (1992) Perron'un dışsal kırılma noktası varsayımını eleştirmişler ve Perronun test istatistiğini farklı bir şekilde ele almışlardır. Zivot ve Andrews dışsallık varsayımını sorgulamışlar ve yerine yapısal kırılmanın içsel olarak gerçekleştiği yani kırımanın tam olarak bilinmediği durumu incelemişlerdir (Barışık, 2008).

Zivot ve Andrews (1992) çalışmasında önce zaman serilerinde meydana gelen yapısal kırımayı temsil edecek, bu kırılmaları modele yansıtacak kukla değişkenler tanımlamışlardır. $T_{1}$ zaman serisinin başlangıç noktasını, $T_{B}$ kırııma anını ve $T_{N}$ de zaman serisinin bitiş noktasını temsil ederse, incelenecek zaman serisi $T_{1}<T_{B}<T_{N}$ olarak ifade edilebilir. Bu tanımlama ışığında Zivot ve Andrews (1992) çalışmasında tanımlanan kukla değişkenler aşağıdaki gibi gösterilebilir:

$$
\begin{gathered}
D^{U}=\left\{\begin{array}{cc}
1 & \text { ĕ̌er } t>T_{B} \text { ise } \\
0 & \text { diğer durumlarda }
\end{array}\right. \\
D^{T}=\left\{\begin{array}{cc}
t-T_{B} & \text { ĕger } t>T_{B} \text { ise } \\
0 & \text { diğer durumlarda }
\end{array}\right.
\end{gathered}
$$

Yukarıda tanımlanan kukla değişkenlerin ilki olan $D^{U}$ serinin ortalamasında meydana gelen kırılmayı açıklamaya yöneliktir. ỉkinci kukla değişken $D^{T}$ ise serinin trendinde meydana gelen yapısal kırılmayı birim kök testi için kurulan modele dahil etmeyi 
amaçlamaktadır. Zivot ve Andrews ADF testi modelini bu kukla değişkenler ile genişleterek aşağıda gösterilen 3 modeli kurmuşlardır:

\section{Model A:}

$\Delta y_{t}=\mu_{A}+\alpha_{A} y_{t-1}+\beta_{A} t+\theta_{A} D_{t}^{U}(\lambda)+\sum_{j=1}^{k} \gamma_{j}^{A} \Delta y_{t-j}+\varepsilon_{t}$

Model B:

$\Delta y_{t}=\mu_{B}+\alpha_{B} y_{t-1}+\beta_{B} t+\phi_{B} D_{t}^{T}(\lambda)+\sum_{j=1}^{k} \gamma_{j}^{A} \Delta y_{t-j}+\varepsilon_{t}$

Model C:

$\Delta y_{t}=\mu_{C}+\alpha_{C} y_{t-1}+\beta_{C} t+\theta_{C} D_{t}^{U}(\lambda)+\phi_{C} D_{t}^{T}(\lambda)+\sum_{j=1}^{k} \gamma_{j}^{A} \Delta y_{t-j}+\varepsilon_{t}$

Model A, B ve C'de $\varepsilon_{t}$ otokorelasyonsuz ve normal dağııımlı hata terimi, $\mathrm{t}$ zamanı $(\mathrm{t}=$ $1, \ldots \mathrm{T})$ göstermektedir. Denklemlerin sağ tarafındaki $\Delta y_{t-j}$ terimi, hata teriminin otokorelasyonsuz olmasını sağlamak amacıyla modele dahil edilmektedir.

Zivot ve Andrews (1992) testinde, ardışık ADF test yöntemi ile örnek içindeki mümkün olan her kırılma noktası için, regresyon denklemi tahmin edilmekte ve tahmin edilen parametreler için $\mathrm{t}$ istatistiği hesaplanmaktadır. Her üç model ile ilgili alternatif hipotez $\alpha$ $=1$ yokluk hipotezi ile test edilmektedir. $\alpha=1$ olması serinin birim kök içerdiği anlamına gelmektedir. Yani yokluk hipotez reddedilemez ise seride kırıma olmadığı ancak birim kök içerdiğini yani durağan olmadığını ifade etmektedir.

Zivot ve Andrews testi aşă̆ıdaki üç alternatif hipotez aracılığı ile uygulanabilir;

Model A: Serinin ortalamasında kırıma vardır ve durağandır.

Model B: Serinin eğiminde kırılma vardır ve durağandır.

Model C: Serinin hem ortalamasında hem de eğiminde kırılma vardır ve durağandır.

Testin uygulanmasında gözlem dönemindeki her bir zaman birimi (yıl, çeyrek, ay vb...) olası kıııma anı olarak alınarak kukla değişkenler oluşturulmakta ve $\alpha$ katsayısının $\mathrm{t}$ istatistikleri elde edilmektedir. Bu süreç gözlem döneminin tümü için uygulandıktan sonra $\alpha$ katsayısının $t$ istatistiğinin minimum elde edildiği yıl olası kırılma yılı olarak belirlenmektedir. Elde edilen $t$ istatistiği Zivot ve Andrews tarafından oluşturulan kritik değerler ile karşılaştırılmaktadır. Eğer elde edilen $t$ istatistiği mutlak değerce kritik değerlerden küçükse serinin birim kök içerdiğini belirten sıfır hipotezi kabul edilmektedir. Elde edilen $t$ istatistikleri mutlak değerce kritik değerlerden büyükse sıfır hipotezi ret edilmekte ve serinin yapısal kırılmayla birlikte durağan olduğunu belirten alternatif hipotez kabul edilmektedir (Barışık ve Çevik, 2008). 


\section{Caner - Hansen (2001) Birim Kök Testi}

Rejim değişimi dinamiği çerçevesinde durağanlık analizi için geliştirilen ve literatürde en sık kullanılan birim kök testi Caner ve Hansen (2001) çalışmasında ortaya konan eşik birim kök testidir. Bu teste Caner ve Hansen, Enders ve Granger testinden farklı olarak zaman serisinde doğrusal olmayan asimetrik bir uyarlama olup olmadığı önce test edilir. Asimetrik uyarlama durumunu Caner ve Hansen eşik etkisi (threshold effect) olarak adlandırmıştır ve önerdikleri teste eşik etkisi testi ismi verilmiştir. Eşik etkisi testi ve daha sonra anlatılacak olan birim kök testi aşağıda tanımlanan modele dayanmaktadır:

$$
\Delta y_{t}=\theta_{1}^{\prime} x_{t-1} I_{\left\{z_{t-m}<\lambda\right\}}+\theta_{2}^{\prime} x_{t-1} I_{\left\{Z_{t-m} \geq \lambda\right\}}+e_{t}
$$

Burada $e_{t}$ iid hata terimi, $I_{\{.\}}$gösterge fonksiyonu, $Z_{t-m}=y_{t-m}-y_{t-m-1}$ olarak tanımlanan eşik değişkeni ve bu tanımda yer alan $m$ ise $m \geq 1$ şartını sağlayan gecikme (delay) parametresidir. Değişkenler matrisi $x_{t-1}$ aşağıdaki gibidir:

$$
x_{t-1}=\left(y_{t-1}, r_{t}^{\prime}, \Delta y_{t-1} \cdots \Delta y_{t-k}\right)^{\prime}
$$

Burada $r_{t}$ sabit ve trend değişkeni içeren deterministik bileşenler matrisidir. Son olarak model (6)'da yer alan $\lambda$ eşik değer olup, bilinmeyen ve tahmin edilmesi gereken değerdir. Bu değer, küçükten büyüğe dizilmiş eşik değişken $Z_{t-m}$ içinden belli oranlarda gözlemin dışlanması ardından elde edilen yeni seri içinde yer alan bir değerdir. Dışlanan küçük değerli gözlem oranı $\pi_{1}$, dışlanan büyük değerli gözlem oranı $\pi_{2}$ ile ifade edilmektedir. $\pi_{1}$ ve $\pi_{2}$ bir birine simetriktir $\left(\pi_{2}=1-\pi_{1}\right)$. Model (6)'daki $\theta$ ise modelin parametrelerini temsil etmektedir:

$$
\theta_{1}=\left(\begin{array}{c}
\rho_{1} \\
\beta_{1} \\
\alpha_{1}
\end{array}\right), \quad \theta_{2}=\left(\begin{array}{c}
\rho_{2} \\
\beta_{2} \\
\alpha_{2}
\end{array}\right)
$$

Bu ifadelerden $\theta_{1}$ 1. rejimin katsayılarını, $\theta_{2}$ ise 2 . rejimin katsayılarını temsil etmektedir. $\left(\rho_{1}, \rho_{2}\right), y_{t-1}$ değişkenine ait katsayılar iken $\left(\beta_{1}, \beta_{2}\right)$ deterministik birleşenlere ait katsayılardır. Son olarak $\left(\alpha_{1}, \alpha_{2}\right),\left(\Delta y_{t-1} \cdots \Delta y_{t-k}\right)$ değişkenlerine ait katsayılardır ${ }^{1}$. Model (6), Chan (1993)'de tanımlanan eşik değer arama algoritması ile En Küçük Kareler (EKK) tahmin yöntemi kullanılarak tahmin edilebilir.

\footnotetext{
${ }^{1}$ Burada bahsedilen katsayı vektörlerinin boyutları değişkenlik gösterebilir. Modelde sadece $\left(\rho_{1}, \rho_{2}\right)$ katsayıları bir vektör değil bir skalerdir.
} 
Caner ve Hansen'nin önerdiği eşik etkisi testi $H_{0}: \theta_{1}=\theta_{2}$ boş hipotezini $H_{1}: \theta_{1} \neq \theta_{2}$ alternatif hipotezine göre test eden bir Sub-Wald ${ }^{2}$ istatistiğidir:

$$
W_{T}(\lambda)=T\left(\frac{\hat{\sigma}_{0}^{2}}{\hat{\sigma}^{2}(\lambda)-1}\right)
$$

Eşitlik (7)'de $T$ toplam gözlem sayısı $\hat{\sigma}_{0}^{2}$ eşik etkisinin olmadığı boş hipotez altında elde edilen doğrusal modelin kalıntı varyansı, $\hat{\sigma}^{2}$ ise model (6)'nın tahmininden elde edilen kalıntıların varyansıdır. Açıkça görüldüğü üzere, Eşitlik (7) ile ifade edilen Wald istatistiğinde boş hipotez altında $\lambda$ tanımlı değildir. Çünkü boş hipotez altında eşik etkisi yoktur ve dolayısıyla bir eşik değer de yoktur. Bu durumda $\lambda$ bir nuisance parametredir. $W_{T}$ istatistiğinin boş hipotez altında asimptotik dağılımı $\lambda$ alacağı değere bağlıdır ve standart değildir. Öyleyse, eşitlik (7) ile ifade edilen Wald istatistiği için asimptotik kritik değerler bulunamaz. Bunun yerine bootstrap ile kritik değer üretilmelidir.

Caner ve Hansen (2001) çalışması alternatif hipotezi çeşitlendirmiş ve bir adet tek, ve bir adet de çift yönlü test önermiştir. Caner ve Hansen (2001) eşik birim kök testinde test edilen hipotezler aşağıdaki gibidir (Parveen ve Silvapulle, 2008):

$H_{0}: \rho_{1}=\rho_{2}=0$ (Boş Hipotez)

$H_{1}: \rho_{1}<0$ ve/ veya $\rho_{2}<0 \quad$ (Kısıtsız, çift taraflı, tam durağanlık alternatif hipotezi)

$H_{2}: \rho_{1}<0$ ve $\rho_{2}<0$ (Kısıtlı, tek taraflı, tam durağanlık alternatif hipotezi)

$H_{3}: \rho_{1}<0$ ve $\rho_{2}=0$ (Kısıtlı, tek taraflı, kısmi durağanlık alternatif hipotezi)

$H_{4}: \rho_{1}=0$ ve $\rho_{2}<0$ (Kısıtlı, tek taraflı, kısmi durağanlık alternatif hipotezi)

Alternatif hipotezlerde tam ve kısmi durağanlık durumları tanımlanmıştır. Buna göre zaman serisi eğer her iki rejimde de durağan ise tam durağanlık durumu, zaman serisi bir rejimde durağan diğerinde değil ise kısmi durağanlık durumu söz konusudur. Caner ve Hansen (2001)'e göre sadece çift taraflı test önermek kısmi durağanlık durumlarını göz ardı edeceğinden eşik birim kök testinde ayrıca tek taraflı bir test de ortaya konmalıdır ${ }^{3}$. Caner ve Hansen tarafından önerilen çift taraflı test istatistiği model (6)'ya dayanan bir Wald istatistiğidir ve aşağıdaki gibi gösterilir:

$$
R_{2 T}=t_{1}^{2}+t_{2}^{2}
$$

\footnotetext{
${ }^{2}$ Eşitlik (4) ile gösterilen test istatistiği eşik değer $\lambda$ 'e bağlıdır. $\lambda$ ise belirtildiği gibi küçükten büyüğe sıralı eşik değişkenin $\pi_{1}$ ve $\pi_{2}$ oranlarında kırpılması ile bulunan seriye ait gözlemlerden birisidir. Sub-Wald ifadesi Superme Wald'dan gelmekte olup, mümkün $\lambda$ 'lar içinde eşitlik (4)'ü en büyük yapacak değerin dikkate alınacağını ifade etmektedir.

${ }^{3}$ Bu durum ile beraber Caner ve Hansen tek taraflı testin çift taraflı teste göre daha fazla güce (power) sahip olduğunu belirtmişlerdir.
} 
Buradaki $t_{1}$ ve $t_{2}$ model (6)'nın EKK tahmininden elde edilen sırasıyla $\hat{\rho}_{1}$ ve $\hat{\rho}_{2}$ ait $t$ istatistiği değerleridir. Bu çift taraflı teste alternatif olarak Caner ve Hansen model (6) ile tahmin edilen $\hat{\rho}_{1}$ ve $\hat{\rho}_{2}$ 'nin negatif değerlerine odaklanarak aşağıdaki tek taraflı testi önermişlerdir:

$$
R_{1 T}=t_{1}^{2} I_{\left\{\hat{\rho}_{1}<0\right\}}+t_{2}^{2} I_{\left\{\hat{\rho}_{2}<0\right\}}
$$

Bu test istatistiğinde $t$ değerleri yine $\hat{\rho}^{\prime}$ ların $t$ istatistiği değerleridir. $R_{1 T}$ istatistiğinde farklı olarak $I$ gösterge fonksiyonu yer almaktadır. Gösterge fonksiyonuna göre her iki rejim için de eğer tahmin edilen $\hat{\rho}$ değeri negatif ise o $\hat{\rho}$ 'ya ait $t$ istatistiği değeri hesaba dahil edilir. $R_{1 T}$ istatistiği boş hipotezi tüm tek taraflı alternatif testlere göre test eder. Fakat bu durumda araştırmacı tek taraflı alternatif hipotezlerden hangisinin test edildiğini anlamak isterse Caner ve Hansen tahmin edilen $\rho$ katsayılarının anlamlılıklarına bakılması gerektiğini belirtirler. Öyleyse, test istatistiğinin hesaplandığı model (6) tahmininde her iki $\hat{\rho}$ tahmini de istatistiki olarak anlamlı ise $R_{1 T}$ istatistiği boş hipoteze karşı $H_{2}$ alternatif hipotezini test edecektir. Yani tek taraflı tam durağanlık durumu test edilecektir. Buna karşın eğer ilk rejime ait $\hat{\rho}_{1}$ tahmini anlamlı $\hat{\rho}_{2}$ tahmini anlamsız ise $R_{1 T}$ istatistiği boş hipoteze karşı $H_{3}$ alternatif hipotezini test edecektir. Tersi durumda ise $R_{1 T}$ istatistiği boş hipoteze karşı $H_{4}$ alternatif hipotezini test eder.

Caner ve Hansen yukarıda gösterilen iki test istatistiğinin asimptotik dağılımlarını eşik etkisinin var olduğu ve var olmadığı iki durum altında incelemişlerdir. Eşik etkisinin olmadığı durma $\left(\theta_{1}=\theta_{2}\right)$ "tanımsız eşik" adını vermişler ve bu durum altında her iki test istatistiği için de asimptotik kritik değerler üretebilmişlerdir. Eşik etkisinin var olduğu durum ise $\left(\theta_{1} \neq \theta_{2}\right)$ "tanımlı eşik" adı altında incelenmiş, bu durumda ise sadece $R_{2 T}$ istatistiği için asimptotik kritik değerler bulunabilmiştir. Caner ve Hansen (2001)'de ortaya konan eşik birim kök test istatistiklerinin asimptotik dağılımlarının incelenmesinin ardından her iki istatistik için bootstrap ile kritik değerler üretilmiştir. Ardından asimptotik testlerin ve bootstrap testlerin 1. Tip hata olasılıkları ve güçleri çeşitli durumlar altında hesaplanmış ve karşılaştırılmıştır. Buna göre bootstrap testlerinin 1. Tip hata olasılığı değerleri baz alınan \%5 düzeye en yakın sonuçları verdiğinden Caner ve Hansen bootstrap testlerinin kullanılmasını önermişlerdir.

\section{BIST SEKTÖREL FIYAT-GETIRI ORANLARI BİRIM KÖK ANALIZLERi}

Çalışmada; BiST 100 Tüm Endeksi, BiST Hizmet Endeksi, BiST Mali Endeksi, BiST Sanayi Endeksi ve BIST Teknoloji Endekslerinin kapanış fiyatlarına göre hesaplanan fiyat ve getiri değerleri bir birlerine bölünerek elde edilen fiyat/getiri oranları kullanılmıştır. Veriler 2009 yılının Ocak ayı ile 2015 yılının Haziran ayı arasında gözlemlenmiştir. Veriler Türkiye Cumhuriyet Merkez Bankası Elektronik Veri Dağıtım Sistemi'nden alınmıştır. 
Bu bölümde sırası ile doğrusal ADF birim kök testi sonuçları, doğrusal olmayan yapısal kırılma birim kök testi Zivot ve Andrews (1992) sonuçları ve rejim değişimi altında çalışan Caner ve Hansen (2001) birim kök testi sonuçları verilmiştir.

Tablo 1: ADF Birim Kök Test Sonuçları

\begin{tabular}{|c|c|c|c|}
\hline Seri & Test İstatistiği & p-değeri & Uygun Gecikme \\
\hline \multirow{3}{*}{ Bist Tüm Endeksi } & -3.166655 & 0.0019 & 2 \\
\hline & $-1.284074^{*}$ & 0.6331 & 2 \\
\hline & -5.363435 & 0.0002 & 2 \\
\hline \multirow{3}{*}{ Hizmet Endeksi } & -2.560637 & 0.0110 & 1 \\
\hline & -1.743919 & 0.4054 & 1 \\
\hline & -4.138626 & 0.0085 & 1 \\
\hline \multirow{3}{*}{ Mali Endeks } & -3.591904 & 0.0005 & 3 \\
\hline & $0.149984^{*}$ & 0.9675 & 3 \\
\hline & -7.325062 & 0.0000 & 6 \\
\hline \multirow{3}{*}{ Sanayi Endeksi } & -4.109222 & 0.0001 & 4 \\
\hline & -0.301832 & 0.9188 & 4 \\
\hline & -6.001698 & 0.0000 & 2 \\
\hline \multirow{3}{*}{ Teknoloji Endeksi } & -3.462772 & 0.0007 & 0 \\
\hline & $-0.570456^{*}$ & 0.8702 & 0 \\
\hline & -3.289620 & 0.0758 & 0 \\
\hline
\end{tabular}

-Test değerleri sırasıyla, yalın ADF modeli, kesme içeren ADF modeli ve hem kesme hem de trend içeren ADF modelleri ile elde edilen test istatistiği değerlerini vermektedir.

-Tüm Birim Kök testleri için maksimum gecikme 6 olarak seçilmiş olup, uygun gecikme Akaike Bilgi Kriterine göre belirlenmiştir.

_“*” işareti birim kökün varlığını işaret eden boş hipotezin reddedilemediği durumları göstermektedir.

Doğrusallık varsayımı altında gerçekleştirilen ADF testi sonuçlarına göre Bist 100 Tüm Endeksi, Mali Endeks ve Teknoloji Endeksi değişkenleri sabit içeren modelde durağan bulunamamış, bunun dışında kalan yalın ve hem sabit hem de trend içeren modeller ile hesaplanan ADF istatistikleri birim kökün varlığını işaret eden boş hipotezi reddedebilmiştir. Hizmet ve Sanayi Endeksi serilerinde ise tüm modellerde birim kökün varlığı reddedilmiştir. Bu sonuçlara göre doğrusallık varsayımı altında serilerin durağan olduğu söylenebilir. 
Tablo 2: Zivot ve Andrews (1992) Birim Kök Testi Sonuçları

\begin{tabular}{|c|c|c|c|c|c|}
\hline Seri & Model & $\begin{array}{c}\text { Gecikme } \\
\text { Sayısı }\end{array}$ & $\begin{array}{l}\text { Kırılma } \\
\text { Zamanı }\end{array}$ & $\begin{array}{c}\text { Test } \\
\text { İstatistiği }\end{array}$ & $\begin{array}{c}\text { \%5 Kritik } \\
\text { Değer }\end{array}$ \\
\hline \multirow{3}{*}{$\begin{array}{l}\text { Bist Tüm } \\
\text { Endeksi }\end{array}$} & Model A & 2 & 06/2012 & -5.684077 & -4.93 \\
\hline & Model B & 2 & $07 / 2013$ & -5.392261 & -4.42 \\
\hline & Model C & 2 & 06/2012 & -5.693352 & -5.08 \\
\hline \multirow{3}{*}{$\begin{array}{l}\text { Hizmet } \\
\text { Endeksi }\end{array}$} & Model A & 1 & $05 / 2010$ & -5.039800 & -4.93 \\
\hline & Model B & 1 & $07 / 2010$ & -4.828259 & -4.42 \\
\hline & Model C & 1 & $06 / 2010$ & $-4.823502 *$ & -5.08 \\
\hline \multirow{3}{*}{$\begin{array}{c}\text { Mali } \\
\text { Endeks }\end{array}$} & Model A & 6 & $06 / 2012$ & -7.619012 & -4.93 \\
\hline & Model B & 6 & $04 / 2011$ & -7.321893 & -4.42 \\
\hline & Model C & 6 & $06 / 2012$ & -7.594615 & -5.08 \\
\hline \multirow{3}{*}{$\begin{array}{l}\text { Sanayi } \\
\text { Endeksi }\end{array}$} & Model A & 2 & $04 / 2012$ & -8.374774 & -4.93 \\
\hline & Model B & 2 & $08 / 2013$ & -6.663712 & -4.42 \\
\hline & Model C & 2 & $04 / 2012$ & -8.559527 & -5.08 \\
\hline \multirow{3}{*}{$\begin{array}{c}\text { Teknoloji } \\
\text { Endeksi }\end{array}$} & Model A & 1 & $06 / 2010$ & $-4.422225^{*}$ & -4.93 \\
\hline & Model B & 1 & $10 / 2013$ & $-4.119973 *$ & -4.42 \\
\hline & Model C & 1 & $06 / 2013$ & $-4.877078 *$ & -5.08 \\
\hline
\end{tabular}

Serilerde bir adet yapısal kırılmanın var olduğu varsayımı altında gerçekleştirilen Zivot ve Andrews (1992) birim kök testi sonuçları Tablo 2'de verilmiştir. Bu sonuçlara göre Hizmet Endeksinin Model C ile gerçekleştirilen birim kök testi serinin durağan olmadığını göstermektedir. Buna ek olarak Teknoloji Endeksi ise tüm model tiplerinde durağan bulunamamıştır. Diğer seriler ise Zivot ve Andrews (1992) birim kök testi sonuçlarına göre tüm model tiplerinde belirlenen yapısal kırılma altında durağandır. 
Tablo3: Caner ve Hansen (2001) Birim Kök Testi Sonuçları

\begin{tabular}{|c|c|c|c|c|c|c|c|}
\hline Seriler & $\begin{array}{l}\text { Eşik Testi } \\
\text { İstatistiği }\end{array}$ & Eşik Değişken & $\begin{array}{l}\text { Eşik Değer } \\
\qquad(\lambda)\end{array}$ & $\begin{array}{c}R_{1 T} \\
\text { İstatistiği }\end{array}$ & $\begin{array}{c}R_{2 T} \\
\text { İstatistiği }\end{array}$ & $\begin{array}{c}\quad t_{1} \\
\text { İstatistiği }\end{array}$ & $\begin{array}{c}\quad t_{2} \\
\text { İstatistiği }\end{array}$ \\
\hline $\begin{array}{l}\text { Bist } \\
\text { Tüm } \\
\text { Endeksi }\end{array}$ & $\begin{array}{l}107.37 \\
(18.24)\end{array}$ & $\begin{array}{c}Z_{t-1}=y_{t-1}-y_{t-6} \\
\text { delay }=5\end{array}$ & -0.009 & $\begin{array}{c}0.75 \\
(13.76)\end{array}$ & $\begin{array}{c}0.75 \\
(13.89)\end{array}$ & $\begin{array}{c}0.092 \\
(3.252)\end{array}$ & $\begin{array}{c}0.8613 \\
(2.9911)\end{array}$ \\
\hline $\begin{array}{l}\text { Hizmet } \\
\text { Endeksi }\end{array}$ & $\begin{array}{c}47.064 \\
(24.657)\end{array}$ & $\begin{array}{c}Z_{t-1}=y_{t-1}-y_{t-5} \\
\text { delay }=4\end{array}$ & $-1.29 \times 10^{-5}$ & $\begin{array}{l}0.000 \\
(2.01)\end{array}$ & $\begin{array}{c}3.98 \\
(19.97)\end{array}$ & $\begin{array}{c}1.92 \\
(3.89)\end{array}$ & $\begin{array}{c}0.534 \\
(3.377)\end{array}$ \\
\hline $\begin{array}{c}\text { Mali } \\
\text { Endeks }\end{array}$ & $\begin{array}{l}134.02 \\
(21.73)\end{array}$ & $\begin{array}{c}Z_{t-1}=y_{t-1}-y_{t-7} \\
\text { delay }=6\end{array}$ & -0.0019 & $\begin{array}{c}0.12 \\
(14.52)\end{array}$ & $\begin{array}{c}0.12 \\
(14.61)\end{array}$ & $\begin{array}{c}0.200 \\
(3.358)\end{array}$ & $\begin{array}{l}0.2833 \\
(3.132)\end{array}$ \\
\hline $\begin{array}{l}\text { Sanayi } \\
\text { Endeksi }\end{array}$ & $\begin{array}{c}29.645 \\
(21.063)\end{array}$ & $\begin{array}{c}Z_{t-1}=y_{t-1}-y_{t-3} \\
\text { delay }=2\end{array}$ & -0.0002 & $\begin{array}{c}0.458 \\
(15.099)\end{array}$ & $\begin{array}{c}0.60 \\
(15.37)\end{array}$ & $\begin{array}{l}-0.38 \\
(3.21)\end{array}$ & $\begin{array}{c}0.6771 \\
(3.1305)\end{array}$ \\
\hline $\begin{array}{l}\text { Teknolo } \\
\text { ji } \\
\text { Endeksi }\end{array}$ & $\begin{array}{c}61.605 \\
(23.435)\end{array}$ & $\begin{array}{c}Z_{t-1}=y_{t-1}-y_{t-3} \\
\text { delay }=2\end{array}$ & -0.0007 & $\begin{array}{c}3.18 \\
(18.81)\end{array}$ & $\begin{array}{c}3.18 \\
(18.81)\end{array}$ & $\begin{array}{c}1.66 \\
(3.72)\end{array}$ & $\begin{array}{c}0.6450 \\
(3.3939)\end{array}$ \\
\hline $\begin{array}{l}\text { - Parant } \\
\text {-Tüm te } \\
\text { - Otokor }\end{array}$ & on düz & er \%5 Bootstrap krit & sadece bir ge & mıştır. & & & \\
\hline
\end{tabular}

Ele alınan beş seri için rejim değişimi dinamiği altında uygulanan Caner ve Hansen (2001) birim kök testi sonuçları Tablo 3'te verilmiştir. Önceki bölümlerde anlatıldığı üzere bu test için önce serilerde anlamlı bir rejim değişimi davranışı olup olmadığı test edilmektedir. ìlk sütunda gösterilen bu testin sonuçlarına göre tüm serilerde belirtilen eşik değişken ve eşik değer altında istatistiki olarak anlamlı bir rejim değişimi (doğrusal olmama) davranışının olduğu saptanmıştır. Bu rejim değişimi davranışı çerçevesinde gerçekleştirilen Caner ve Hansen (2001) birim kök testi, gerek tek taraflı gerekse çift taraflı test istatistiği hesaplarına göre serilerin tümünün birim kök içerdiği yani durağan olmadığı sonucunu ortaya koymaktadır.

\section{TARTIŞMA}

Çalışmada zaman serilerinde gözlenen doğrusal olmayan dinamikler açıklanmış ve iki önemli doğrusal olmayan ekonometri literatürüne değinilmiştir. Bu bağlamda takip eden bölümlerde doğrusal olmayan iki temel dinamik çerçevesinde geliştirilen ve literatürde en sık kullanılan birim kök testleri ayrıntıları ile anlatılmıştır. Gerek doğrusal olmayan birim kök testlerinin temelini oluşturması bakımından gerekse doğrusal olmayan birim kök testi sonuçları ile karşılaştırma yapılması için çalışmada doğrusal birim kök testi olan ADF testi de detaylı bir şekilde anlatılmış ve uygulamada bu teste de yer verilmiştir.

Doğrusal birim kök testi ADF sonuçlarına göre üç seride sabit içeren model ile gerçekleştirilen analiz sonucu birim kökün varlığı kabul edilmiştir. Ancak diğer tüm 
modeller ve seriler için doğrusalıı varsayımı altında birim kökün varlığı reddedilebilir. Bir başka ifade ile serilerin doğrusal olduğu varsayımı ile serilerin durağan olduğu söylenebilir.

Yapısal kırıma altında gerçekleştirilen Zivot ve Andrews (1992) birim kök testi sonuçları incelendiğinde zaman serilerine hâkim olan doğrusal olmayan dinamiklerin etkileri görülmeye başlamıştır. Tablo 2'ye göre Hizmet Endeksi fiyat-getiri oranı serisi sadece Model C için birim kök içerdiği söylenebilir. Ancak diğer model tiplerinde birim kök içermemesi sonucunda Hizmet Endeksi fiyat-getiri oranı serisinin hem sabit hem de trende kırıma olması durumunda durağan olmadığı fakat sadece sabit veya sadece trende kırılma olması durumlarında durağan olduğu sonucu ortaya çıkmaktadır. Ancak Teknoloji Endeksi fiyat-getiri oranı serisine baktığımızda tüm yapısal kırılma durumlarında birim kökün varlığı reddedilememektedir. Dikkat edilecek olursa, aynı seri doğrusal ADF testinde durağan olarak değerlendirilmiş, birim kökün varlığı reddedilebilmiştir. İşte karşılaşılan bu örnek seride yapısal kırıma olması durumunda gerçekleştirilen doğrusal birim kök testlerinin ne kadar yanıltıcı sonuçlar doğurabileceğini ortaya koymaktadır. Bu sebepten ötürü eğer ele alınan zaman serisine etki eden doğrusal olmayan bir etkinin (Yapısal kırılma veya rejim değişimi gibi.) varlığından şüpheleniliyor ise ilgili zaman serisi artık doğrusal olmayan yöntemler ile incelenmelidir. Örneğin yapısal kırılma altında durağan olmayan Teknoloji Endeksi fiyat-getiri oranı serisi ile bir başka seri arasında anlamlı bir eşbütünleşme ilişkisi olup olmadığını test etmek isteyelim. Bundan böyle Teknoloji Endeksi fiyat-getiri oranı serisi için doğrusal eşbütünleşme analizleri olan Engle ve Granger (1987) eşbütünleşme ve Johansen (1988) eşbütünleşme analizleri gerçekleştirilemez. Bu seri için artık yapısal kırıma altında çalışan eşbütünleşme analizi olan Gregory ve Hansen (1996) analizi gerçekleştirilmelidir.

Rejim değişimi dinamiği altında çalışan Caner ve Hansen (2001) testi sonuçları Tablo 3'de sunulmaktadır. Caner ve Hansen zaman serilerindeki rejim değişimini dikkate alan bir birim kök testi önermeden önce seride anlamlı bir rejim değişimi yani eşik etkisi olup olmadığını geliştirdikleri bir Wald istatistiği ile test edilmesi gerektiğini belirtmişlerdir. Bu bağlamda çalışmada ele alınan tüm fiyat-getiri oranı serilerine Caner ve Hansen'nin geliştirdiği eşik etkisi sınaması uygulanmış ve bu sınamalar sonucunda tüm serilerde anlamlı bir rejim değişim dinamiği, bir başka ifade ile anlamlı bir eşik etkisi bulunmuştur. Bu nedenle serilere rejim değişimini dikkate alan bir birim kök testinin uygulanması gerekmektedir.

Ele alınan tüm seriler için anlamlı bir rejim değişim dinamiği bulunması aynı zamanda ilgili serilerin hangi eşik değişken için anlamlı bir doğrusal olmayan davranışa sahip olacağını tespit eder. Eşik değişkenin sahip olacağı maksimum gecikme sayısı kuramsal çerçeve bölümünde de bahsedildiği üzere "delay parameter" olarak adlandırılmakta idi ${ }^{4}$. Delay parametresi ise serinin doğrusal olmayan davranışını açıklamak için önemlidir. Bist Tüm Endeksi fiyat-getiri oranı serisi için elde edilen sonuçları yorumlayalım. Tüm Endeksi için

\footnotetext{
${ }^{4}$ Türkçe literatürde "lag" kelimesi "gecikme" olarak çevrilmiştir. Bu kelime bir regresyon modeline dahil edilecek gecikmeli değişkenleri ifade etmek için kullanılmaktadır. Örneğin ADF testinde otokorelasyon sorunundan kaçınmak için modellere eklenen bağımlı değişkenin gecikmeli serileri için "lag” ifadesi kullanılır. Bu nedenle rejim değişimi literatüründe bahsi geçen "delay" kelimesinin gecikme olarak çevrilmesi doğru olmamaktadır. Bu sebeple çalışmada "delay" kelimesine Türkçe bir karşılık önerilmemiş ve kelime olduğu gibi kullanılmıştır.
} 
delay parametresi 5 olarak tahmin edilmiştir. Öyleyse eşik değişken $Z_{t}=y_{t}-y_{t-5}$ olarak tanımlanır. Bu değişken şunu demek ister: Bist Tüm Endeksi fiyat-getiri oranı serisinde " 5 aylık bir sürede" meydana gelen değişim eğer eşik değer -0.009 'u geçer veya bu değere eşit olursa serinin davranışını birinci rejim için tahmin edilen model açıklar. Eğer eşik değişken, eşik değer -0.009 'un altında olursa serinin davranışını 2. rejim için tahmin edilen model açıklar. Ancak bu konuna hatırlatılması gereken önemli bir nokta $Z_{t}$ değişkeninin bir dönem gecikmelisinin $\left(Z_{t-1}=y_{t-1}-y_{t-6}\right)$ eşik modeli oluştururken dikkate alınmasıdır. Çünkü burada seride meydana gelen 5 aylık değişimin 1 dönem sonra modele etki ettiği varsayılmaktadır. Bu açıklamalar ışığında diğer serilerin doğrusal olmayan rejim değişimi davranışları da anlaşılabilir.

Çalışmada kullanılan fiyat-getiri oranları serileri için gerçekleştiren eşik birim kök testi Caner ve Hansen (2001) testi sonuçlarına göre serilerin tamamı birim kök içermektedir. Tablo 3'de yazarların önerdiği tek ve çift yönlü test istatistiği değerleri ve her rejim için elde edilen $t$ istatistiği değerleri verilmiştir. Bununla birlikte her test için elde edilen \%5 anlamlılık düzeyi bootstrap kritik değerleri de sunulmuştur. Dikkat edileceği üzere bazı serilerde tek ve çift yönlü testlerde aynı test istatistiği değerleri elde edilmiştir. ilgili durum Caner ve Hansen (2001) çalışmasında da belirtilmiş, bazı seriler için tek ve çift yönlü birim kök istatistiği değerlerinin birbirine çok yakın ve aynı değer olabileceği ve test sonuçlarının benzer olacağı belirtilmiştir (Caner ve Hansen, 2001: 1578). Bu sebepten ötürü yazarlar yapmış oldukları uygulamada çift yönlü teste yer vermemişlerdir. Bu çalışmadaki uygulamada ise eşik birim kök istatistiği sonuçları tüm seriler için tek, çift yön fark etmeksizin aynı sonuçları vermiş, her durumda serilerde birim kökün varlığı kabul edilmiştir.

Serilerde rejim değişimi dinamiği çerçevesinde durağan olmadıklarının anlaşılması, gerçekleştirilecek ampirik çalışmaların bir sonraki adımlarında rejim değişimi literatürünün ilgili başııklarının takip edilmesi gerekliliğini ortaya koymaktadır. Yapısal kırılma göz önüne alınarak gerçekleştirilen Zivot ve Andrews (1992) birim kök testi sonuçlarının yorumlandığı paragrafda verilen örnek hatırlanacak olursa, rejim değişimi dinamiği altında da Teknoloji Endeksi fiyat-getiri oranı serisi ile herhangi bir başka seri arasında eşbütünleşme analizi gerçekleştirilmek istenirse, rejim değişim literatüründe yer alan Hansen (1999) ve Kapetanios ve Shin (2006) eşik eşbütünleşme analizleri kullanılmalıdır.

\section{SONUÇ}

Çalışma zaman serilerinde etkili olan doğrusal olmayan dinamikleri tanımlamayı ve bu dinamiklerin uygulamada ve teoride ne denli önemli olduğunu anlatmayı amaçlamıştır. Gerekli kuramsal açıklamalardan sonra ekonometrik çalışmaların ilk aşaması olan durağanlık araştırmaları üzerinden doğrusal olmayan etkilerin zaman serilerinin durağanlığı üzerinde nasıl bir etkide bulundukları gösterilmiştir. Açıkça anlaşılmıştır ki doğrusalık varsayımı altında elde edilen durağanlık analizi sonuçları ile doğrusal olmayan dinamiklerin varlığı durumunda elde edilen birim kök testi sonuçları arasında önemli farklılıklar mevcuttur. Caner ve Hansen (2001) çalışmasında önerilen eşik etkisi testi ile serilerde anlamlı bir doğrusal olmayan davranış yani rejim değişim davranışı mevcuttur. İktisadi ve özellikle anlık değişimleri daha sık gözlemlenebildiği finansal zaman serilerinde 
doğrusal olmayan etkilerin gözlemlenmesi çok yüksek bir ihtimaldir. Bu nedenle özellikle finans alanında yapılan ekonometrik çalışmaların doğrusal olmayan dinamikler üzerinde yoğunlaşması ve Türkçe finans literatürünün doğrusal olmayan yöntemler ile gerçekleştirilecek ampirik çalışmalarla zenginleştirilmesi gerekmektedir. Daha güvenilir finansal analizler gerçekleştirebilmek ve Türkiye'de finansal öngörüleri daha sağlıklı yapılabilmek için bu çalışmalar elzemdir.

\section{KAYNAKLAR}

AKDi, Yılmaz (2010), Zaman Serileri Analizi (2. Baskı) Ankara: Gazi Kitabevi.

Banerjee, A., Lumsdaine, R. L., and Stock, J.H. (1992), Recursive and Sequential Tests of the Unit Root and TrendBreak Hypothesis: Theory and International Evidence, Journal of Business and Economic Statistics, Sayı: 10, p.271-287.

Barışık ve Çevik (2008), İşsizlikte Histeri Etkisi: Uzun Hafıza Modelleri, Kamu-i̇ş, Cilt: 9, Sayı: 4.

Caner, M. ve Hansen, B.E. (2001). Threshold Autoregression with a Unit Root. Econometrica, 69, p.1555-1596.

Chan, K. S. (1993), Consistency and Limiting Distribution of the Least Squares Estimator of a Threshold Autoregressive Model, The Annals of Statistics, Sayı: 21, 520-533.

Christiano, L. J. (1992). Searching for a Break in GNP, Journal of Business and Economic Statistics, Sayı: 10, p.237249.

Dickey, D. ve Fuller, W. (1979), Distribution of the Estimators for Autoregressive Time Series with a Unit Root. Journal of the American Statistical Association, Sayı: 74, p.427-431.

Dickey, D.A. ve Fuller, W.A. (1981), "Likelihood Ratio Statistics for Autoregressive Time Series with a Unit Root. Econometrica, Sayı:49, p.1057-1072.

Enders, Walter (2010), Applied Econometric Time Series (3. Baskı) New York: John Wiley ve Sons Inc.

Engle, R. F. ve Granger, C. W. J. (1987), Co-Integration and Error-Correction: Representation, Estimation and Testing. Econometrica, Sayı:55, p.251-276.

Gregory, A. Ve Hansen, B. (1996), Test for Cointegration in Models with Regime and Trend Shifts, Oxford Bulletin of Economic and Statistics, Sayı: 58(3), p.555-560.

Gujarati, D. N. (2006), Temel Ekonometri (4.Baskı), (Çev.: Ümit Şensen, Gülay Günlük Şensen) İstanbul: Literatür.

Hansen, B. E. (1999), Testing for Linearity, Journal of Economic Surveys, Sayı: 3(5), p.551-576.

Johansen, S. (1988), Statistical Analysis of Cointegration Vectors, Journal of Economic Dynamics and Control, Sayı: 12, p.231-254.

Kapetanios G., Shin, Y. ve Snell, A. (2006), Testing for Cointegration in Nonlinear Smooth Transition Error Correction Models, Econometric Theory, Sayı: 22, p.279-303.

Kennedy, P. (2006). Ekonometri Kılavuzu (6.Baskı), (Çev.: Muzaffer Sarımeşeli ve Şenay Açıkgöz) Ankara: Gazi Kitabevi.

Parveen, T. ve Silvapulle, P. (2008), Self-Exciting Threshold Autoregressive Models for Testing Asymmetric Roots: Extensions and Empirical Evidence from G7 Countries Real Interest Rates. Markets and Models, Policy Frontiers in the AWH Phillips Tradition, The 49th Annual Conference of the New Zealand Association of Economists and The Australasian Meeting of the Econometric Society sempozyumunda sunulmuş bildiri, Wellington, New Zealand.

Perron, P. (1989), The Great Crash, the Oil Price Shock, and the Unit Root Hypothesis, Econometrica, Sayı: 57,p.1361-1401 
Perron, P. (1997), Further Evidence on Breaking Trend Functions in Macroeconomic Variables, Journal of Econometrics, Sayı: 80 (2), p.355-385.

Perron, P. and Vogelsang, T. J. (1992), Nonstationarity and Level Shifts with an Application to Purchasing Power Parity, Journal of Business and Economic Statistics, Sayı: 10, p.301-320.

Ramanathan, R. (2002), Introductory Econometrics with Applications (5. Baskı) Harcourt College Publishers.

Tong, H. ve Tim, K. S. (1980), Threshold Auto regression, Limit Cycles and Cyclical Data. Journal of Royal Statistical Society, Sayı: 42, p.245-292.

Tong, Howell (1978), On a Threshold Model in Pattern Recognition and Signal Processing, (ed. C.H. Chen), NATO ASI Series E: Applied Sc., Sayı: 29, p.575-586.

Tong, Howell (1983), Threshold Models in Non-linear Time Series Analysis (1. Baskı) New York: Springer-Veriag.

Yavuz, N. Ç. (2006), Türkiye'de Turizm Gelirlerinin Ekonomik Büyümeye Etkisinin Testi: Yapısal Kırılma ve Nedensellik Analizi, Doğuş Üniversitesi Dergisi, Sayı: 7(2), p.166-167.

Zivot, E. ve Andrews, D. (1992), Further Evidence on the Great Crash, the Oil Price Shock and the Unit Root Hypothesis. Journal of Business and Economic Statistics, 10, p.251-270. 